\title{
The Reconstruction of Guilin's Urban Ecological Landscape Based on the Concept of Sponge City
}

\author{
Xinling $\mathrm{Li}^{1}$, Jinye Wang ${ }^{1}$, and $\mathrm{Ning} \mathrm{Li}^{2,3, *}$ \\ ${ }^{1}$ College of Tourism, Guilin University of Technology, Guilin 541006, China \\ ${ }^{2}$ Bowen College of Management Guilin University of Technology, Guilin 541006, China \\ ${ }^{3}$ Key Laboratory of spatial information and mapping of Guangxi, Guilin 541006, China
}

\begin{abstract}
Guilin is an international tourist city famous for its landscape, but the prominent contradiction in water usage becomes one of the key factors that influences and restricts the construction and development of the city. As an effective measure to relieve the contradiction of urban water usage, the concept of "sponge city" has achieved success in many places. Thus, building Guilin urban ecological landscape on the basis of the concept of "sponge city" is of great significance for the effective relief of the contradiction in water usage and the realization of sustainable development. Academic studies point out that for the purpose of the construction of sponge city, the construction of Guilin's urban ecological landscape first need to adopt sponge strategies in urban residential areas, transform or build a virtuous circulating green space system to collect, purify and store rainwater in an effective way. Secondly, build rainwater collection, purification, storage facilities or systems extensively and replenish urban ecological water reserve in the grey system of the city, according to the concept of "sponge". Thirdly, considering the large area of Guilin city parks, build rainwater self-use rain systems extensively in city parks based on the concept of sponge and substantially reduce external ecological water reserve. Fourthly, reinforce training and learning related to the concept of "sponge city" and the implementation of "sponge city" policies.
\end{abstract}

\section{Introduction}

With the rapid development of urbanization, cities are faced with all kinds of ecological and environmental problems and urban landscape has changed accordingly. How to build a harmonious and unified city between man and natural ecological landscape is a common concern for scholars, designers, governments and general public. Both the foreign view on garden city and the idea to combine nature, landscape ecology planning and ecosystem management emphasize that landscape design should get close to nature or be naturalized. Some famous scholars in China also come up with the theory of building harmonious and sustainable urban ecological landscape between nature and human beings. Under the influence of the notion of sustainable development, some developed countries began to suggest building a "sponge city". Taking the theory of "sponge city" as a starting point, "Best Management Practices", "Low Impact Development", as well as sustainable drainage system, consider the quantity and quality of water, facilitate the collection and utilization of rainwater, pursue the organic combination between rainfall flood management facilities and landscape and build a harmonious sustainable city on the basis of water environment ${ }^{[1]}$. Due to the popularization of the concept of "sponge city" in China, the construction of some urban ecological landscape adopt "sponge" measures to maintain good ecological functions of the cities, such as artificial wetland, rainwater garden, roof greening, sunken green land, grassed swale and ecological park. Guilin is a famous scenic tourist city and also a prestigious historical and cultural city in China ${ }^{[2]}$. In an official approval to construct "sponge city" issued by the state, Guilin is also selected as one of the pilots for the construction of "sponge city". To make Guilin sustainable, more beautiful and healthy, we intend to probe into the "sponge" reconstruction of Guilin's urban ecological landscape.

\section{The Current Characteristics of the Construction of Guilin's Urban Ecological Landscape}

\subsection{The Social and Cultural Characteristics of the Historical City of Guilin}

Guilin is a world-renowned scenic tourist city and also a prestigious historical and cultural city in China. In the long process of formation and development, Guilin culture has been integrated by a variety of distinctive cultural factors. From a dynamic, open and evolutionary angle, the social and cultural characteristics of the

\footnotetext{
* Corresponding author: guilinlining@163.com
} 
historical city of Guilin can be summarized as the following four aspects: (1) political culture. In history, the First Emperor of Qin ordered to excavate Ling Canal. In the Han Dynasty, Emperor Wu set up Jiujun. In the Tang Dynasty, Li Jing built Guizhou City. Through many renovations in the Song Dynasty, finally Jingjiang Princess City was built in the Yuan Dynasty. These events marked changes and development of the political cultural form and system of Guilin in history. (2) Educational culture. According to historical records, the earliest formal education in Guilin can be traced back to Dali period of the Tang Dynasty. Guizhou Governor considered it necessary to esteem Confucius and read classics, to make people simple, honest and unspoiled, so he established the first prefectural-level school in Guilin at the foot of Solitary Beauty Peak. After that, some government officials and wealthy people also donated money to build schools, and public and private schools sprung up everywhere ${ }^{[3]}$. In the Song Dynasty, Guilin became the ruling center of Guangxi and attracted a large number of people to work and travel here. This formed a good cultural atmosphere in Guilin. The literary atmosphere in Guilin also flourished. In the Yuan Dynasty, educational culture in Guilin suffered a setback temporarily. But in the Ming and Qing dynasties, under the vigorous push of local officials and active advocacy of scholars and literati, cultural education in Guilin soon regained vitality. (3) Landscape culture. Guilin has its own distinctive cultural form. One of them is landscape culture Yan Yanzhi, a famous poet in the Southern Dynasties, often visited Dengfeng, Guilin, expressed his aspiration with poems and left many oftquoted verses about Guilin's landscape. The cliff carvings left by Wang Zhenggong, a poet in the Southern Song Dynasty, on Solitary Beauty Peak included the most well-known verse about Guilin-"East or west, Guilin's landscape is best." Guilin's landscape attracted many famous poets, who promoted the development of ancient Guilin's landscape literature indirectly. Landscape paintings are also an integral part of Guilin's landscape culture. Guilin's natural landscape environment per se is a marvelous scroll of Chinese landscape and therefore attracts many artists to come and paint for Guilin's landscape and drives the development of Guilin's landscape paintings. (4) Religious culture. Guilin has a long history of religious culture. As early as in the Jin Dynasty, the earliest Buddhist temple-Pingle Longxing Temple was built in Guilin. In the Tang Dynasty, Guilin became the Buddhist center in southern China. During the Yuan Dynasty, there was a lot of growth in religion, especially the rise of Islam. The Ming and Qing dynasties were stages where Islam grew rapidly. The introduction of Islam made Buddhism, enrichs the connotations of Guilin's religious culture and has a significant impact on the cultural life of Guilin people.

\subsection{Overview of the Construction of Guilin's Urban Ecological Landscape}

\subsubsection{The evolution process of urban ecological}

\section{landscape}

Urban landscape often changes with the construction and development of cities. Different historical cultures and people's ideas in each period contribute to different urban landscape characteristics in different periods. Guilin is a southwest city with a history of more than two thousand years. Guilin's landscape is also deposited from rich historical culture and humanistic art. Taking time as a clue, we can see characteristics of the construction of Guilin's urban ecological landscape in different periods: (1) Ancient natural landscape. Ancient Guilin people had a naïve view on landscape. They revered and worshiped nature. Following the philosophy of "conforming to nature", urban landscape was transformed and added on the basis of the original appearance of nature. Thus, urban landscape at that time reserved the landscape characteristics specific to Guilin, i.e., "grotesque mountains and clean waters". (2) Modern and contemporary landscape that combines artificial with natural. After reform and opening up, urban construction has grown rapidly. To improve the economic level of the city and quality of human settlements, Guilin's urban landscape construction is dominated by people-oriented landscape that combines artificial with natural. It is supposed to not only satisfy people's needs for sightseeing and recreation, but also guarantee the economic development of Guilin as a scenic tourist city. (3) Modern harmonious landscape between man and nature. Under the influence of urbanization and industrialization, the urban ecological environmental problems in Guilin are increasingly prominent. The redevelopment of the city is restricted. To solve this problem, people uphold the principle of "respecting nature" and harmony between man and nature and begin to renovate and build ecological and sustainable urban ecological landscape.

\subsubsection{The composition characteristics of urban ecological landscape}

Urban ecological landscape is composed of natural landscape, economic landscape and cultural landscape ${ }^{[5]}$. It can support a city's demand for sustainable development and is an advantageous tool to improve the spatial quality of public places and also an essential condition to improve the city's habitability ${ }^{[1]}$. Due to the influence of topography, geomorphology, hydrology and other natural conditions, there exists a particular natural ecological landscape in local area- karst landscape. These conditions also make the construction of Guilin's urban ecological landscape and development very diversified. The economic landscape in Guilin includes energy utilization, transportation, infrastructure, land use and industrial structure, etc. Only by handling the relationship and development in all aspects properly can the construction and development of Guilin's urban ecological landscape be ensured. Guilin's cultural landscape enshrines long-standing traditional culture. History, customs and other connotations are rendered and expressed through ecological landscape, making Guilin possess peculiar urban ecological landscape 
characteristics.

\subsubsection{Main problems with the construction of urban ecological landscape}

The substantive role of the construction of urban ecological landscape is to protect urban ecological environment and reduce factors that pollute urban ecological environment, thus improving the quality of urban human settlements and making the development of urban ecological environment ecologically sustainable and cyclical. At present, the construction of Guilin's urban ecological landscape is faced with some problems, mainly including: (1) The construction of urban ecological landscape is not "ecological". Some landscape is built only for the sake of beauty. The scientificity is not taken into full account and the ecology of landscape is ignored. For example, urban pollutants are not disposed properly. Urban landscape designs give more consideration to sensory effects than ecological benefits and fail to consider the harmony and unity between man and nature. As a result, a lot of construction wastes too much energy or causes great damages to the environment. (2) The structure of urban ecological landscape is too monotonous. At present, since natural environment is destroyed, there are increasingly fewer natural components in Guilin urban ecological landscape. It is mainly composed of green space. The little remaining green space is concentrated in squares or parks, very scarce around streets or residential areas. The spatial distribution is very uneven. (3) There is a lack of good combination between natural landscape and the city. During urban construction, there is a lack of concrete guiding measures to protect natural landscape and highlight the characteristics of landscape, which leaves the construction of urban ecological landscape in an embarrassing situation- without rules to follow.

\section{Reconstruction Paths and Measures of Guilin's Urban Ecological Landscape}

\subsection{The concept of sponge city and the reconstruction of Guilin's ecological landscape}

Influenced by urbanization, the economic level and human settlements in Guilin have improved a lot. But with that come many serious ecological environmental problems, especially the contradiction in water ecological environment destroys Guilin's urban ecological landscape and seriously affects the image of Guilin as an international tourist city. In an official approval to construct "sponge city" issued by the state, Guilin is also selected as one of the pilots for constructing "sponge cities". "Sponge city" is realized using "naturally depositing, naturally permeating and naturally purifying" ecological infrastructure. It gives play to the permeating effect of topography, geomorphology and other primitive ecological backgrounds on rainwater and the purifying effect of vegetation and wetland, etc. on water quality and combines natural with artificial, to enable cities to absorb and drain rainwater ${ }^{[6]}$. Recently, the State Council has officially replied and agreed that Guilin can build a national innovation demonstration zone on the agenda of sustainable development, with the theme of sustainable utilization of landscape resources ${ }^{[7]}$. For this reason, the reconstruction of Guilin's urban ecological landscape should be combined with the theory of "sponge city", so as to realize the sustainable development goal of Guilin's urban ecological landscape.

\subsection{Reconstruction principle of Guilin's urban ecological landscape under the concept of sponge city}

From the current concept and construction path of "sponge city", as well as the process and composition characteristics of the construction of Guilin's urban ecological landscape, the reconstruction of Guilin's ecological landscape should adhere to the following principles: (1) Ecology first. The development and construction of cities should protect rivers, lakes, wetlands and other water sensitive areas, give priority to natural drainage system and low impact development facilities, realize natural impounding, natural permeation, natural purification and sustainable water circulation, improve the ability of nature to recover water ecosystem and maintain the good ecological functions of cities $^{[8]}$. (2) Exploring local characteristics. For scenes that are of historical value, commemorative value and artistic value, it is necessary to explore, utilize, maintain and preserve them consciously, to make urban space and landscape operated in the past coherent ${ }^{[9]}$. At the same time, it is necessary to apply modern scientific and technological achievements and create urban spatial environment with local and temporal characteristics in multiple elements of urban landscape, so as to meet the requirements for the development of times ${ }^{[10]}$. (3) Sustainable development. The construction of Guilin's urban ecological landscape should consider long-term interests, rather than just immediate interests, lay emphasis on the development of ecological energy and utilization of renewable energy technology, regard the development of ecological energy and renewable energy technology as an organic whole and implement it and finally let natural ecological environment reach a self-circulating state in the city.

\subsection{Reconstruction paths of Guilin's ecological landscape under the concept of sponge city}

\subsubsection{Sponge strategies for urban residential areas}

Based on the current architectural characteristics of Guilin's urban residential areas, Guilin's urban residential areas are divided into traditional residential areas and high-rise residential areas, for ease of considering "sponge construction". Traditional residential areas in the old downtown of Guilin reflect local cultural and historical characteristics and should be preserved. Without prejudice to the original local historical styles and features, green space in traditional 
residential areas can be reconstructed as sunken interhouse rainwater gardens to collect rainwater on streets and between houses, purify and infiltrate rainwater through four processes: pebbles, plants, fine sand and soil. On the other hand, parking lots, roads and green belts may be transformed into permeable grassed bricks, permeable roads and biological detainment zones to collect surrounding rainwater, to prevent rainwater accumulation from affecting residents' life. Finally, considering the vehicle loads on roadways, it is not recommended to use permeable pavement, but rather, to use green belts on both sides of the road to collect and digest rainwater runoff on the pavement. The new downtown of Guilin is an area newly built and developed in recent years. For the sake of economic development, it is necessary to build a lot of high-rise buildings. In view of this fact, when constructing highrise buildings, it is necessary to consider "sponge" construction. For example, we can design community garden paths in high-rise residential areas as permeable pavement, add grassed swales to both sides of the paths, collect surrounding rainwater and store it in the underground tanks for recycling. Combined with permeable pavement, open drains and biological detention facilities, rigid squares in residential area can be designed as a virtuous circulating system that integrates the collection, purification and storage of rainwater into one.

\subsubsection{Sponge strategies for urban roads}

As one of the main impermeable underlying surface of cities, urban roads account for more than $30 \%$ of the construction land ${ }^{[12]}$. From the drainage of traditional pipelines in Guilin, prominent problems mainly include the high pressure of road drainage and serious pavement pollution. To solve these problems, we can resort to some "sponge" measures, for example, ecological tree pools, design a series of coherent tree pools as potential water collecting devices and maximize their role in the collection and filtration of rainwater runoff. There is also biological detention pond, which is a narrow and linear sunken landscape space with abundant landscape plants and regular shapes. It can also collect and purify rainwater. Finally, isolation belts in the middle of roads. Originally, detention ponds on both sides of roads and green belts in the middle are not related to each other. Combined with the status quo of the transverse slope of roads, they can be integrated as a new drainage and greening ecosystem. This is a new strategy to cope with road flooding. Isolation belts in the middle of roads, as a common form of road greening, are of great potential utility value in the construction of sponge cities. Using sponge design strategies, urban roads can not only solve rainwater drainage, pollutant discharge and other problems, but also produce huge economic, ecological and aesthetic benefits.

\subsubsection{Sponge strategies for city parks}

Guilin is an international tourist city. To satisfy the needs of the general public and visitors from all over the world, Guilin has built many city parks. The green space of city parks is large. In view of this fact, we may as well build rainwater self-use rain systems extensively in city parks based on the concept of sponge and greatly reduce external ecological water reserve. For example, on park pavement, we can turn to materials with good permeability, to solve the problem of pluvial flooding in park roads effectively, set ditches besides roads, to effectively collect rainwater runoff, in case it flushes the pavement. In addition, in city parks, we can build sunken rainwater gardens, which not only ensure the collection of surrounding rainwater runoff, but also avoid damage to the landscape image of parks as a result of rainfall flood and waterlogging. Plant landscape in rainwater garden has an ornamental effect, too. Finally, we can build large sunken green space, which is able to collect surface runoff in surrounding buildings, roads and squares, etc. and reduce loss caused by waterlogging in the region during rainfall flood. Meanwhile, a water storage module under sunken green space can store and recycle rainwater.

\subsubsection{Safeguard strategies for the construction of sponge city}

In order to realize the construction of sponge city, Guilin government should organize citizens to participate in training and learning related to the concept of "sponge city". Public participation is the foundation. Through publicity and education, the public sense of participation can be improved, to make the construction of sponge city popular and universal among the public and play the role of democratic supervision. Additionally, we should give more support to policy making, administrative system, planning and design, etc. of "sponge city", so as to ensure that the construction of sponge city gets along in an orderly and effective way.

\subsection{Safeguard mechanism for the construction of Guilin's urban ecological landscape}

\subsubsection{To strengthen the construction of ecological compensation mechanism}

Guilin government should speed up ecological compensation legislations for natural reserves, important ecological function areas, mineral resource development, as well as the protection of basin water environment, determine the scope, object, way and standard of compensation in the form of law and form a complete and unified social policy document, to avoid the shorttermism of ecological compensation system ${ }^{[13]}$.

\subsubsection{To perfect supervision policies on ecological environmental governance}

To strengthen the protection management of ecological environment, we should proceed from management mechanism and perfect management mechanism, to 
make the protection of Guilin's ecological environment have rules to follow, enforce an environmental pollution accountability system, adhere to the principle of "whoever exploits should protect, whoever pollutes should treat", put environmental protection into practice in various regions and departments and avoid shirking when environmental problems occur.

\subsubsection{To form a social synergy mechanism}

We should give full play to the guiding and supervising role of news media, publicize the quality of ecological environment, pollution control, corporate environmental behavior and other information in Guilin in a timely manner, expose typical illegal behaviors that undermine Guilin urban ecological construction; fully listen to the wills of the public, strengthen public supervision and encourage all walks of life to get involved in the reconstruction of Guilin's urban ecological landscape; strengthen publicity and education, emphasize the harmonious development between man and nature, the ecological concept of co-existence and common prosperity, cultivate citizens' sense of responsibility to cherish and care for the good ecology; disseminate major decisions made by the party and the state on the construction of ecological civilization spontaneously, guide citizens to develop good habits and join hands to maintain a good ecological environment in Guilin ${ }^{[13]}$.

\section{Conclusion}

Urban ecological landscape is not a pure green planting and the image of the city's surface decoration, but as for urban ecological environment protection and natural resources recycling and heritage city cultural history of a number of important functions such as ecological system. The problem of water ecology environment caused by Guilin urbanization should be faced positively, and "sponge city" should be regarded as the target and principle of urban ecological landscape remolding. Finally, it is hoped that the research and thinking of this paper can contribute to the realization of the harmony between nature and society and the sustainable development of Guilin.

This work was supported by the National scientific and technological support projects (2012BAC16B04), the Guangxi education department youth teacher basic ability improvement project ( 2017KY1360) and GuangXi Key Laboratory of Spatial Information and Geomatics Program (Contract No. GuiKeNeng 151400734,163802518 and 163802531).

\section{References}

1. S. Ranhao, X. Zhongliang, C. Liding, L. Fen.Theoretical Framework and Key Techniques of Urban Ecological Landscape Research[J]. AES,32,7(2012)
2. R. Yuanyuan. The Study on the Development of Historical and Cultural Tourism Resources in Guilin [D]. Guangxi Normal University, (2006)

3. Y. Yuan. Research on Wisdom Experience of Human Settlements with Shan-Shui Environment in Guilin Historical City [D]. Xi'an University of Architecture and Technology, (2013)

4. H. Guanghui, C. Xibo, Z. Yingli. The Characteristics of Scenic City of Guilin and Its Protection [J]. GR, 3(2003)

5. L. Ruonan. Landscape Planning in Eco-city Planning [J]. MASAT, 2(2010)

6. L. Lan, L. Feng. The Key Scientific Issues and Thinking on the Construction of "Sponge City" [J]. AES, ,38,7(2018)

7. Our Correspondent, S. Min, Trainee Journalist, H.Fengchao, The Construction of a National Innovation Demonstration Zone on the Agenda of Sustainable Development in Guilin Sets Sail [N]. Guilin Daily, (2018)

8. D. Weiqin, K. Donglian, D. Tianmin. Reflecting on the Construction of Sponge City and Water and Soil Conservation in Production and Construction Projects $[\mathrm{C}]$.The third meeting and academic seminar of the professional committee of urban water and soil conservation ecological construction of China water and soil conservation society, (2015)

9. W. Mingfei. A Simple Analysis of Urban Landscape Planning and Design [J]. JOCJU, 3(1998)

10. W. Xiaoliang, W. Peirong. A Study on Trinity Theory in Modern Urban Landscape Planning [J]. C E\&TH, 19(2009)

11. L. Chengkai. Research on Sponge City Design in Urban Ecological Landscape [D]. Anhui University, (2016)

12. Z. Shenglan. On the Construction Technologies of Municipal Road Rainwater Drainage Projects [J]. CWT, 4(2011)

13. D. Xuguang, H. Keliang, W. Ruijian, H. Xudong. Thoughts on the Establishment and Perfection of Safeguard Mechanism for Guangzhou's Eco-city Construction [J] ASFTAR, 2(2015)

14. W. Sufang. A Brief Analysis on the Ecological Compensation Mechanism for Soil and Water Conservation [J]. SAM, 6(2012) 